\title{
Simulation of fan formation using a debris mass model
}

\section{Formation d'un cône de déjection, simulation par un modèle de masse de débris}

\author{
SHAO SONGDONG, Research Fellow, Division of Environmental and Water Resources Engineering, School of Civil and Structural \\ Engineering, Nanyang Technological University, Singapore 639798. E-mail: csdshao@ntu.edu.sg \\ EDMOND LO YAT-MAN, Associate Professor, Division of Environmental and Water Resources Engineering, School of Civil and \\ Structural Engineering, Nanyang Technological University, Singapore 639798. E-mail: cymlo@ntu.edu.sg. (Correspondence Author)
}

WANG GUANGQIAN, Professor, Department of Hydraulic Engineering, Tsinghua University, Beijing 100084, China. E-mail: dhhwgq@mail.tsinghua.edu.cn

\begin{abstract}
Based on the particle-in-cell computing method, a debris mass model has been established to simulate debris flow fan formation over large downstream areas. Under the assumption that the debris medium is an assembly of many small, identical debris particle masses, the overall flow behavior is obtained by averaging the flow parameters of neighboring debris masses at fixed grid points. The equation of motion for each debris mass is based on the depthaveraged Navier-Stokes equation in two horizontal dimensions. The friction slope of debris flow is modeled by combining the effects of both the liquid phase (slurry composed of water and fine particles) modeled as a Bingham fluid and solid phase (coarse particles) in the debris mixture. The rheological parameters are evaluated according to the density and particle size distribution of the debris material. Convergence of the method is demonstrated by repeatedly doubling the number of debris masses employed in the computation until insignificant change is observed. The debris mass model is demonstrated through a prototype application to a documented 1991 debris flow deposited in the lower reach of the Shawan Ravine in Yunnan Province, China. The final alluvial fan was formed by eight consecutive debris flow events, each lasting about 2000 seconds with a discharge rate of $250 \mathrm{~m}^{3} / \mathrm{s}$. The simulation results are in good agreement with field observations. The general features of debris fan development and configuration are well predicted.
\end{abstract}

\section{RÉSUMÉ}

Sur la base de la méthode numérique "particle-in-cell », on a mis au point un modèle de masses de débris pour simuler la formation de cônes de déjection par coulées sur de larges zones aval. En faisant l'hypothèse que le milieu de la coulée est composé de nombreuses petites masses particulaires de débris identiques, on obtient le comportement de l'écoulement global en moyennant, aux nœuds d'une grille fixe, les paramètres d'écoulement des masses de débris voisines. Les équations du mouvement pour chaque masse de débris sont basées sur les équations de Navier-Stokes moyennées en hauteur et à deux dimensions horizontales. La pente de frottement de la coulée de débris est modélisée en combinant les effets, à la fois, de la phase liquide (la boue composée de l'eau et des particules fines) représentée par un fluide de Bingham, et de la phase solide (les particules grossières) dans le mélange de débris. Les paramètres rhéologiques sont évalués en fonction de la distribution de densité et de taille de particules du matériau. On démontre la convergence de la méthode en doublant plusieurs fois le nombre de masses de débris utilisées dans le calcul jusqu'à ce qu'on n'observe plus de changement significatif. Le modèle de masse de débris est validé par une application prototype à une coulée de débris, documentée en 1991, qui s'est déposée dans le tronçon inférieur du ravin de Shawan dans la province du Yunnan en Chine. Le cône alluvial final avait été formé par huit coulées consécutives, chacune d'elles durant environ 2000 secondes avec un débit de $250 \mathrm{~m}^{3} / \mathrm{s}$. Les résultats de la simulation sont en bon accord avec les observations. Les caractéristiques générales de la formation du cône de déjection et de sa configuration sont bien prédites.

\section{Introduction}

Debris flow disasters have been recognized as a critical problem in steep mountainous regions with geological, geomorphologic and climatological combinations that favor such flows. Many debris flow disasters are associated with the downstream alluvial fan, which usually occurs in the most populated area of the gully basin. Thus the formation process and the shape of the debris fan have been the focus of continuing research ( $\mathrm{Li}$ et al. 1983; Takahashi 1991; and Wan and Wang 1994). Various methods have been reported with regard to the assessment of the alluvial fan. These methods include theoretical and numerical methods, experimental approaches and field investigations.

Jeyapalan et al. (1983) provided various analytical methods for predicting the features of a 1-D laminar flow failures of mine tailings dams. A Bingham plastic rheological model was used to represent the behavior of tailings material. Huang and Garcia (1997) treated the laminar mud flow with a Bingham-plastic law and used the method of matched asymptotic expansions for a dambreak problem. First-order solutions in the outer and inner regions of the flow were derived. Shieh and Tsai's (1997) experimental results showed that the deposition profiles of the debris flow fan in a stable stage could be described by Gaussian curves both in the longitudinal and transverse directions of the flow path and the shape of the fringe of debris fan is similar to a half of an ellipse. They also proposed a semi-empirical relationship between the total volume of a debris fan and the maximum length, width and thickness of the fan. By investigating the remnant trail of previous debris deposits, estimating the potential volume of unstable solid materials in a gully, and interviewing of local inhabitants, Wang and Yu (1997) had delineated the hazard zones of debris fan into different hazard levels in various mountainous regions of Beijing. Numerical models to simulate the debris fan formation have been receiving increasing attention in recent years. Shallow-water equations or kinematic wave equations are often used for debris flow modeling (Takahashi 1987; Mizuyama 1987; Arattano and 
Savage 1994). Usually the debris flow is assumed to be homogeneous and the detailed internal interactions either between solid and solid particles or between solid particles and liquid phase are simplified or neglected. The simulation models differ chiefly in how they represent friction forces and employ various numerical solution procedures. For example, MacArthur and Schamber (1986) presented a 2-D finite element model for application to a simplified overland topography. The fluid properties were considered to be those of a Bingham fluid, whose static shear stress is a function of the fluid viscosity and yield strength. O'Brien et al. (1993) employed a 2-D finite difference procedure and a quadratic rheological model developed from field and laboratory mudflow data to simulate flooding conditions ranging from clear water to hyper-concentrated sediment flows. Han and Wang (1996) incorporated a 3-D rheological model for Bingham body into their numerical model to describe the relationship between the stress tensor and the rate of strain in terms of the viscoelastic and plastic behavior of the debris flow. They studied the transient and high-speed features of dam-breaking debris flows. A similar problem was addressed by Frenette et al. (1997) using a Galerkin finite element approach. Laigle and Coussot (1997) incorporated a Herschel-Bulkly model established by Coussot (1994) for steady regimes into their models for transient flows. The notable features of the derived wall friction force expressions are that the parameters are not fitted but can be directly deduced from rheological measurements. A recent review by Parker (1999) gave a comprehensive evaluation of the progress made in the experimental, theoretical and numerical modeling of fans and put forward some suggestions for future research.

The particle-in-cell computing method put forward by Harlow (1964) provides a good tool for numerically treating free surface flood flow in two horizontal dimensions. Tetzlaff and Harbaugh (1989) combined it with sediment erosion and sedimentation theories to model the low-concentration sediment-laden flow. Later, Wang, Shao and Fei $(1997,1998)$ applied the PIC method to simulate flood flow in the Jingjiang River Flood-diversion Area and debris flow in the Yunnan Province. In that formulation only the bed friction force was incorporated into the total friction force. It was later found that the model could be improved by additionally considering the effects of viscosity in the interior of the inner debris flow. This viscosity force arises from the horizontal velocity difference between adjacent fluid particles and is similar to the lateral momentum transfer between the main channel and the flood plain in compound channel flow (Abida and Townsend 1994). The main features of this paper lie in two aspects: Firstly, it employs the PIC method to treat the free surface and moving boundary of the 2-D debris flow in an effective way. Secondly, it employs a simple but effective rheological model incorporating the friction from the liquid slurry modeled as a Bingham fluid, and the bed friction from the coarse solid particles. The relevant rheological parameters are obtained from the density and particle size distribution of the debris material. It is also assumed that the downstream alluvial fan is mainly composed of debris material flushed out from the upstream region and the material from local bed erosion and deposition contribute only a small part of the debris fan. Therefore, erosion and deposition of the bed are not in- corporated for simplicity. However, the good agreement between model simulations and field observations shows that the presented model provides a simple and effective way to simulate debris fan formation over large downstream regions.

\section{Model principles}

The debris mass model is based on the assumption that the entire debris medium is an assembly of many small, identical and homogeneous debris masses. Assuming that the flow occurs only in the two horizontal dimensions, the motion of each debris mass is computed based on the depth-averaged Navier-Stokes equation. This equation is then solved through a step-by-step numerical integration in the time domain. Consequently, the velocity and spatial positions of all debris masses are obtained. By averaging these parameters at fixed grid points, the overall flow behavior in the computational domain and the development of alluvial fan are simulated.

Variables including the topographic elevation, flow depth and velocity are represented at fixed points on a $2 \mathrm{D}$ square grid covering the modeled area. Variables including the velocity and spatial coordinates of each debris mass are represented at the individual debris mass location which moves with the flow. Flow parameters at the grid point represent averages within a square region surrounding each grid point. For example, the flow depth at a grid point is calculated by

$$
h_{i j}=\frac{N_{i j} \Delta V}{A}
$$

where $h_{i j}=$ flow depth at grid point $i j ; N_{i j}=$ number of debris masses within the square grid surrounding the grid point; $\Delta V=$ volume of one debris mass; and $A=$ area of the square grid region.

Similarly, the flow velocity at a grid point is calculated as the average velocity of all debris masses within the square grid region surrounding the grid point, i.e.,

$$
\vec{v}_{i j}=\frac{1}{N_{i j}} \sum_{b=1}^{N_{i j}} \vec{v}_{b}
$$

where $\vec{v}_{i j}=$ flow velocity at grid point; and $\vec{v}_{b}=$ velocity of debris mass $b$.

\section{Equations of motion}

The simulation of alluvial fan formation over downstream areas involve significantly larger horizontal than vertical scales. Thus the flow conditions can be simulated in two horizontal dimensions. By modifying the momentum equation for water flow, the corresponding equation for debris flow is written as

$$
\frac{\partial \vec{v}}{\partial t}+(\vec{v} \cdot \nabla) \vec{v}=-g \nabla\left(Z_{0}+h\right)-g \vec{S}_{f}+\frac{\mu_{m}}{\rho_{m}} \nabla^{2} \vec{v}
$$

where $\vec{v}=$ depth-averaged flow velocity; $t=$ time; $g=$ gravita- 
tional acceleration; $Z_{0}=$ topographic elevation; $h=$ flow depth; $\vec{S}_{f}=$ bed friction slope for debris flow; $\mu_{m}$ and $\rho_{m}=$ viscosity and density of the debris flow mixture.

As formulated above, the total friction force of the debris flow consists of two parts, one from the bed and the other from the viscosity of the debris fluid. This viscosity force arises from the horizontal velocity difference among adjacent debris masses and transfers the lateral momentum among them. Apart from the bed, the friction also arises at the side-walls or banks when they are incorporated into the computational domain. The treatment procedures will be discussed in the section on Initial/Boundary Conditions.

In Lagrangian form Equation (3) can be written as

$$
\frac{D \vec{v}}{D t}=-g \nabla\left(Z_{0}+h\right)-g \vec{S}_{f}+\frac{\mu_{m}}{\rho_{m}} \nabla^{2} \vec{v}
$$

The above equation governs the motion of the individual debris mass and can be written using finite differencing in time and space as (Tetzlaff and Harbaugh 1989)

$$
\frac{\vec{v}_{b, t+\Delta t}-\vec{v}_{b, t}}{\Delta t}=g \vec{S}_{b, t}-g \vec{S}_{b f, t}+\frac{\mu_{m}}{\rho_{m}} \frac{\left(\vec{v}_{i, j+1}^{t}+\vec{v}_{i, j-1}^{t}+\vec{v}_{i+1, j}^{t}+\vec{v}_{i-1, j}^{t}\right)-4 \vec{v}_{i j}^{t}}{(\Delta S)^{2}}
$$

where $\vec{v}_{b, t+\Delta t}$ and $\vec{v}_{b, t}=$ velocity of debris mass $b$ at time $t+\Delta t$ and $t$ respectively; $\Delta t=$ time increment; $\vec{S}_{b, t}=$ flow surface slope at the location of debris mass $b ; \vec{S}_{b f, t}=$ bed friction slope of debris mass $b ; \vec{v}_{i j}^{t}=$ velocity at grid $i j$ at time $t$; and $\Delta S=$ horizontal grid spacing in both $x$ and $y$ directions. The $i j$ in $\vec{v}_{i j}^{t}$ corresponds to the grid point closest to debris mass $b$. The evaluation of $\vec{S}_{b, t}$ requires interpolation between the values at neighboring grid points. This is performed using a biquadratic interpolation function.

Denoting the summation of the right side of Equation (5) as $\vec{a}_{b, t}$, the updated velocity of a debris mass $b$ is given by

$$
\vec{v}_{b, t+\Delta t}=\vec{v}_{b, t}+\vec{a}_{b, t} \Delta t
$$

The spatial position is then computed from

$$
\vec{X}_{b, t+\Delta t}=\vec{X}_{b, t}+\frac{\vec{v}_{b, t+\Delta t}+\vec{v}_{b, t}}{2} \Delta t
$$

where $\vec{X}_{b, t+\Delta t}$ and $\vec{X}_{b, t}=$ spatial coordinates of debris mass $b$ at time $t+\Delta t$ and $t$, respectively.

\section{Modeling of bed friction slope for debris flow}

The bed friction slope for debris flow is needed for numerical calculations. Here the two-phase flow rheological model of Wang (1994), which is to sum the effects of the liquid slurry (composed of water and fine grain) and the coarse solid grains, is adopted. The 2-D bed friction slope of the liquid slurry is modeled as a Bingham fluid for fully developed uniform flow (e.g. Huang and
Garcia 1997)

$$
\vec{S}_{l}=\frac{\tau_{B}}{\gamma_{m} h} \vec{S} g n(\vec{v})+\frac{2 \mu_{B} \vec{v}}{\gamma_{m} h^{2}}
$$

where $\vec{S}_{l}=$ friction slope for the liquid slurry; $\vec{S} g n(\vec{v})=$ signs of velocity in $x$ and $y$ directions; $\tau_{B}=$ Bingham yield stress of the slurry; $\mu_{B}=$ Bingham viscosity of the slurry; and $\gamma_{m}=$ specific weight of the debris flow mixture.

The bed friction slope of coarse particles is modeled on the rubbing effects of solid grains on the bed for simplicity. This is expressed as

$$
\vec{S}_{s}=C_{s} \frac{\rho_{s}-\rho_{l}}{\rho_{m}} \tan \varphi \vec{S} g n(\vec{v})
$$

where $\vec{S}_{s}=$ friction slope for the solid grains; $\rho_{S}=$ density of solid grains; $\rho_{l}=$ density of the liquid slurry; $C_{\mathrm{s}}=$ volume concentration of coarse grains; and $\varphi=$ frictional angle.

Combining Equation (8) and (9) and writing it in discrete form gives the bed friction slope for a debris mass $b$ as

$$
\vec{S}_{b f, t}=\frac{\tau_{B}}{\gamma_{m} h_{b, t}} \vec{S} g n\left(\vec{v}_{b, t}\right)+\frac{2 \mu_{B} \vec{v}_{b, t}}{\gamma_{m} h_{b, t}^{2}}+C_{s} \frac{\rho_{s}-\rho_{l}}{\rho_{m}} \tan \varphi \vec{S} g n\left(\vec{v}_{b, t}\right)
$$

Here the evaluation of $h_{b, t}$ also requires interpolation between the values at neighboring grid points. This is also performed as a biquadratic interpolation function.

\section{Evaluation of rheological parameters}

Fei's formula (1991) are adopted here to evaluate the rheological parameters of the liquid slurry in Equation (10). His work is based on the debris flow observation and data analysis from the Xiaojiang River Basin in Yunnan Province. The debris mass model proposed here will also be applied to a field case located in the same river basin. Thus Fei's formula provides a good basis to evaluate the rheological parameters for numerical simulations. Fei correlated the relationship between the density of debris flows and the grain size gradations in about 1000 debris samples covering 40 field cases of debris flow events. He found that for most viscous debris flows $\left(\rho_{m}>1900 \mathrm{~kg} / \mathrm{m}^{3}\right)$, the content of fine grains with diameter $d_{0}<2.0 \mathrm{~mm}$ remains approximately the same, and the increment of the density of debris mixture is caused only by the existence of coarse solid grains with diameter $>2.0 \mathrm{~mm}$. Thus a value of $d_{0}=2.0 \mathrm{~mm}$ separating the fine grains of the liquid slurry and coarse particles is employed here for numerical simulations.

By data analysis and empirical fitting to rheological measurements, Fei proposed the following formula to evaluate the rheological parameters of liquid slurries, in which the effects of both the grain size and distribution are incorporated. 
The Bingham yield stress in $\mathrm{N} / \mathrm{m}^{2}$ is represented by

$$
\tau_{B}=0.098 \exp \left(8.45 \frac{C_{f}-C_{f 0}}{C_{f m}}+1.5\right)
$$

where $C_{f}=$ volume concentration of the liquid slurry; $C_{f m}=$ upper limit volume concentration of the liquid slurry and $C_{f 0}=$ critical volume concentration from which the slurry changes from a Newtonian fluid to a Bingham fluid. The relationship between $C_{f 0}$ and $C_{f m}$ is represented by

$$
C_{f 0}=1.26 C_{f m}^{3.2}
$$

The upper limit volume concentration $C_{f m}$ reflects the maximum possible filling of fine grains in the slurry and is represented by

$$
C_{f m}=0.92-0.2 \log \sum \frac{p_{i}}{d_{i}}
$$

where $d_{i}$ and $p_{i}=$ diameter (in $\mathrm{mm}$ ) and weight percent of grains in the grain size distribution of fine particles.

The viscosity of the liquid slurry is represented by

$$
\mu_{B}=\mu_{0}\left(1-k \frac{C_{f}}{C_{f m}}\right)^{-2.5}
$$

where $\mu_{0}=$ viscosity of water and $k=$ correction for the effects of closed water among grains and is usually taken as unity. The viscosity of the debris flow mixture assumes a similar form as Equation (14)

$$
\mu_{m}=\mu_{B}\left(1-\frac{C_{s}}{C_{d m}}\right)^{-2.5}
$$

where $C_{d m}=$ upper limit volume concentration of the debris mixture. It reflects the maximum possible filling and closeness of both fine and coarse grains in the debris flow mixture and is usually taken as 0.80 .

\section{Initial/boundary conditions and convergence analysis}

The specification of the initial and boundary conditions in the debris mass model is quite straightforward. Initial conditions provide the topographic elevation at all grid points at the beginning of the computation. If the modeled domain initially contains flow, the velocity and spatial coordinates of existing debris masses and the flow velocity and depth at grid points are also specified.

Two kinds of boundary conditions are required. Flow boundary conditions provide the input of debris masses, whose spatial locations are specified by the entrance of the alluvial fan. This is also the physical boundary between the river and the fan area. The number and velocity of these input masses are evaluated accord- ing to the available discharge information $Q$ at the flow inlet, the volume of each debris mass $\Delta V$ and time increment $\Delta t$.

Wall boundary conditions are provided at the side-walls or banks which are incorporated into the computational domain. The velocity at these grid points are set to be zero to represent the no-slip boundary. In computation, debris masses will change their directions after colliding with these physical boundaries. They will also lose a fraction of their energy and momentum. No theoretical method is readily available to exactly evaluate this process. For simplicity, the collision process is assumed to be elastic, except that the velocity of debris masses after collision is reduced by half to approximate the energy loss due to the interaction with the physical boundary (Wang, Shao and Fei 1998).

Because individual debris masses are discrete points and cannot deform as the real flow does, the number of masses employed in the computation must be sufficiently large to give a realistic flow simulation. This requirement is essential for numerical convergence. Thus convergence is achieved by repeatedly doubling the number of debris masses (or equivalently halving the volume of each debris mass) into the computational domain until the numerical solutions from consecutive doubling are essentially unchanged.

Equation (1) indicates that a debris mass will be allocated to its nearest grid point for the calculation of the relevant flow parameters. Rapid and large translation of many debris masses during a time step $\Delta t$ will certainly lead to discontinuities or unsteadiness of flow parameters at grid points, and also instabilities in the numerical computation. Thus the value of $\Delta t$ is restricted to ensure that the maximum translation distance of each debris mass during each time step is less than at least half the grid spacing, i.e.

$$
\left|\vec{X}_{b, t+\Delta t}-\vec{X}_{b, t}\right|<0.5 \Delta S
$$

This constraint is used to control $\Delta t$ in the computation and is equivalent to the Courant condition in explicit time stepping. The value of the grid spacing $\Delta S$ also affects the convergence and accuracy of the simulation through the viscosity term in Equation (5). This is also reduced until numerical convergence is observed in the results.

\section{Model application in shawan ravine of yunnan province}

\section{Introduction of the Shawan Ravine}

The Shawan Ravine is located in the upper and middle reach of the Xiaojiang River Basin in Yunnan Province, China. The deposition region of the Lower Shawan Ravine covers an area of about $1.32 \times 10^{6} \mathrm{~m}^{2}$. It is a meandering gully with a wide-shallow trapezoidal cross section. The bottom width ranges from $300 \mathrm{~m}$ to 600 $\mathrm{m}$ and the side slope ranges from $2^{\circ}$ to $5^{\circ}$. The average longitudinal slope angle is less than $4^{\circ}$. The initial ground surface is irregular and unsymmetrical about its central longitudinal line.

The Shawan Ravine is well known for its long history of debris flow activities and hazards. During the summer of 1991, a series of debris flow events occurred within the ravine basin. The allu- 
vial fan caused extensive property damage and threatened the existence of hundreds of residents downstream. The debris flow was triggered by heavy storms and had a recurrence period of 20 years.

Several months after the 1991 debris flow, detailed field investigations were carried out by the Dongchuan Debris Flow Observation and Research Station, Chinese Academy of Sciences (Xiong, et al 1992). General features of the debris fan were measured, including the final horizontal extent of the fan, one longitudinal surface elevation profile and one cross-sectional surface elevation profile near the entrance of the fan. It was estimated that the alluvial fan covered an area of $34 \times 10^{4} \mathrm{~m}^{2}$ and the total volume of deposits was $4 \times 10^{6} \mathrm{~m}^{3}$. These data were used to test the debris mass model performance.

\section{Computation parameters}

A plan view of the computational domain is shown in Figure 1. The dimension of the modeled area is $975 \mathrm{~m}$ by $750 \mathrm{~m}$ and the square grid cell has spacing $\Delta S=25 \mathrm{~m}$. The river mouth is located on the left side with an inlet width of about $25 \mathrm{~m}$. Thus the modeled domain includes only the fan area. The assumed physical boundaries are approximated by zigzag grid lines shown and are composed of two parts. The solid lines on the left part correspond to the physical ravine banks which will strongly influence the development of the debris fan. The dotted lines on the right are imaginary boundaries and are chosen sufficiently large to contain the debris fan.

According to the field investigations of debris deposits, the 1991 debris flow was a viscous debris flow with the density of flow mixture $\rho_{m}=2150 \mathrm{~kg} / \mathrm{m}^{3}$. Several deposit samples at different locations were collected to analyze the grain size distribution, of which a typical one is shown in Figure 2. The $\phi$ scale is used due to the large range of particle sizes

$$
\phi=\log _{2} d
$$

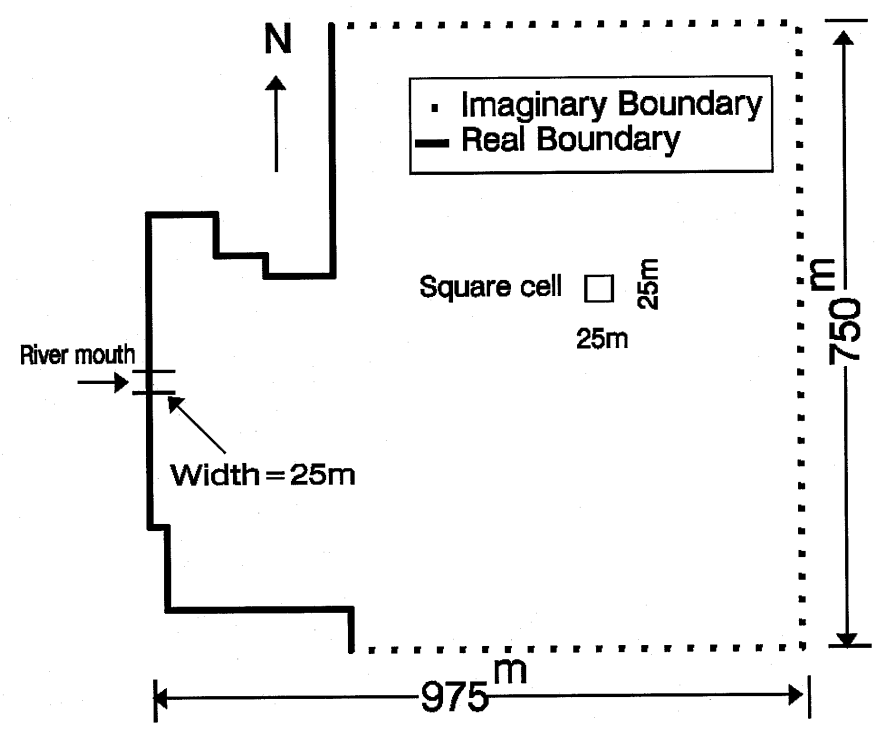

Fig. 1. Plan View of Computational Domain

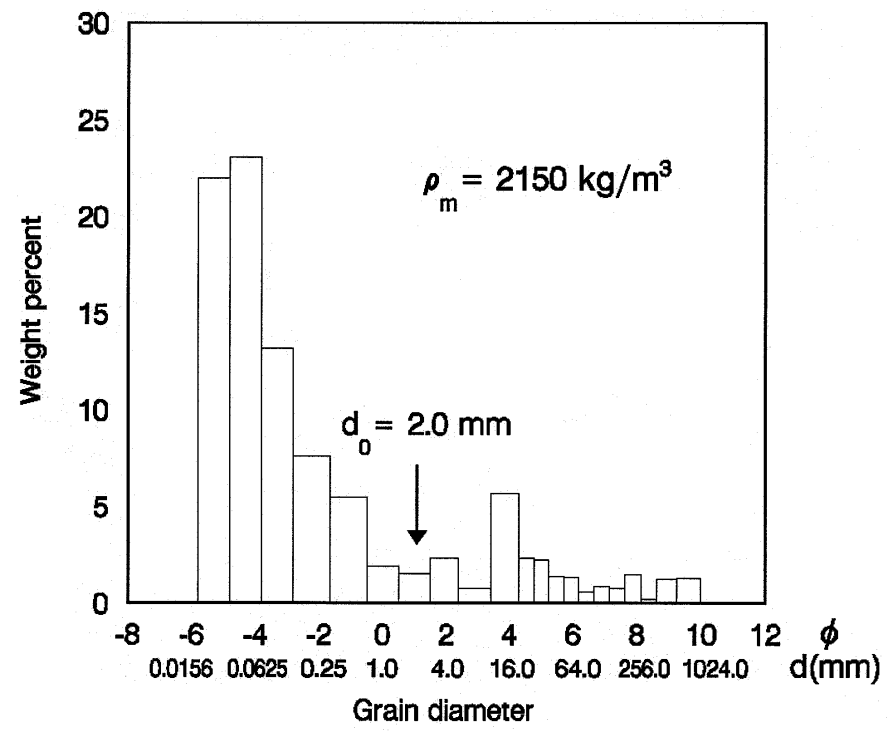

Fig. 2. Grain Size Distribution of 1991 Viscous Debris Flow in Shawan Ravine

where $d$ is particle diameter in $m m$.

By employing the density of solid grains $\rho_{s}=2650 \mathrm{~kg} / \mathrm{m}^{3}$ and the value of diameter separating liquid slurry and coarse grains $d_{0}=$ $2.0 \mathrm{~mm}$ (viscous debris flow), the density of the liquid slurry $\rho_{l}=$ $1660 \mathrm{~kg} / \mathrm{m}^{3}$ and volume concentration of coarse grains $C_{s}=0.45$ were calculated from the grain size distribution of Figure 2. The Bingham yield stress $\tau_{B}$, viscosity $\mu_{B}$ of the liquid slurry and viscosity $\mu_{m}$ of the debris flow mixture were evaluated to be 25 $\mathrm{N} / \mathrm{m}^{2}, 0.05 \mathrm{~N} \cdot \mathrm{s} / \mathrm{m}^{2}$ and $0.5 \mathrm{~N} \cdot \mathrm{s} / \mathrm{m}^{2}$, respectively by Fei's formulas (1991) as given above. The evaluation of friction angle of solid grains $\varphi$ was based on Bagnold's experiment (1954). It was considered that both the viscosity of the inner fluid and the inertial interactions among solid grains play an equally important role during the debris fan formation. Thus a value close to the transitional region in Bagnold's grain shear experiment was adopted, i.e. $\tan \varphi=0.6$.

It was difficult to determine precisely the discharge condition at the entrance of the alluvial fan, i.e., the upstream boundary condition. However, the recorded inlet flow data and field observation of fan deposits (Xiong et. al 1992) showed that of all the debris flow events, eight of them contribute significantly to the formation of the fan. Each had approximately a total input deposits of about $5 \times 10^{5} \mathrm{~m}^{3}$ and a mean discharge rate of $250 \mathrm{~m}^{3} / \mathrm{s}$. The flow stopped between each event. Thus a constant discharge rate of $250 \mathrm{~m}^{3} / \mathrm{s}$ and duration time of 2000 seconds were employed as the boundary condition for each of the eight debris flow events. By gradually doubling the number of debris masses (halving the volume of each debris mass $\Delta V$ ) into the computation domain and halving the time increment $\Delta t$ during different simulations, it was shown that converged solutions were obtained when the time increment was about $0.5 \mathrm{~s}$ and the total number of debris masses employed during each debris flow event reached 20000, corresponding to the volume of each debris mass $\Delta V=25 \mathrm{~m}^{3}$. The choice value of $\Delta t$ further met the requirement of Equation (16). Thus during each time increment $\Delta t$ five debris masses were supplied from the boundary and they were evenly distributed along 
the flow inlet located at the entrance of the alluvial fan which had a width of $25 \mathrm{~m}$ according to recorded data. We note that while the absolute value of $\Delta V$ seemed large, it was sufficiently small when compared with the area of the grid cell.

\section{Computation results and analysis}

The computed alluvial fan formation in the horizontal plane by the eight different debris flow events is shown in Figure 3. The computed central longitudinal surface elevation profile and the cross-sectional surface elevation profile near the entrance of the fan are shown in Figures 4 and 5, respectively. In these figures the measured values correspond to the final stage of the fan are given for comparison. It is seen that the overall agreement is good and the debris mass model presented behaves well.

The convergence in the solution is seen by changing the number of debris mass and the grid spacing as shown in Figure 6. In one run the final extent of the debris fan is computed by parameters employed before except that the number of debris mass is doubled. Thus 40000 debris masses are involved and the volume of each debris mass is halved to $\Delta V=12.5 \mathrm{~m}^{3}$. Another run is performed by reducing the grid spacing to $\Delta S=12.5 \mathrm{~m}$ and other computational parameters being unchanged. It is seen that the numerical results are almost identical in all three cases, which indicates that convergence is obtained.

From the above simulations, the general features of the alluvial fan are obtained. The development of the upper part of the fan (i.e., from the entrance inlet to a distance of about $300 \mathrm{~m}$ downstream) is controlled both by the local topography and by the ravine banks, with the latter playing a more important role. This can be seen in Figure 7 which is the contour map for the computed surface elevation of the final alluvial fan. The lower part of the debris fan is only affected by the local relief and extends freely in

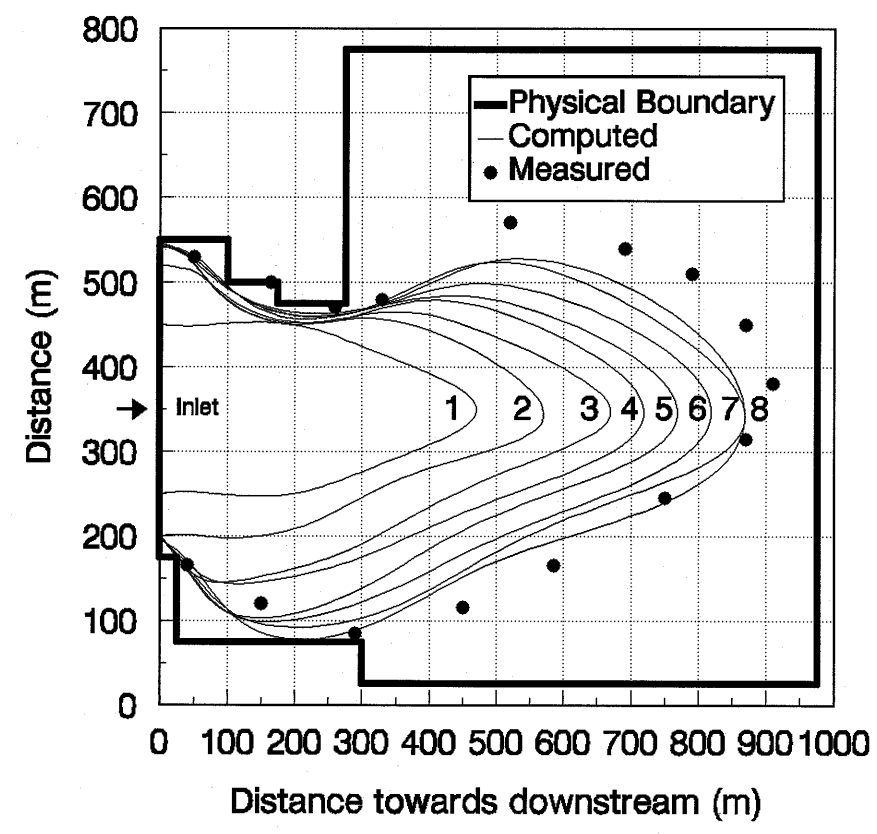

Fig. 3. Plan View of Alluvial Fan Formation by Eight Debris Flow Events. Measured Values Correspond to Final Alluvial Fan

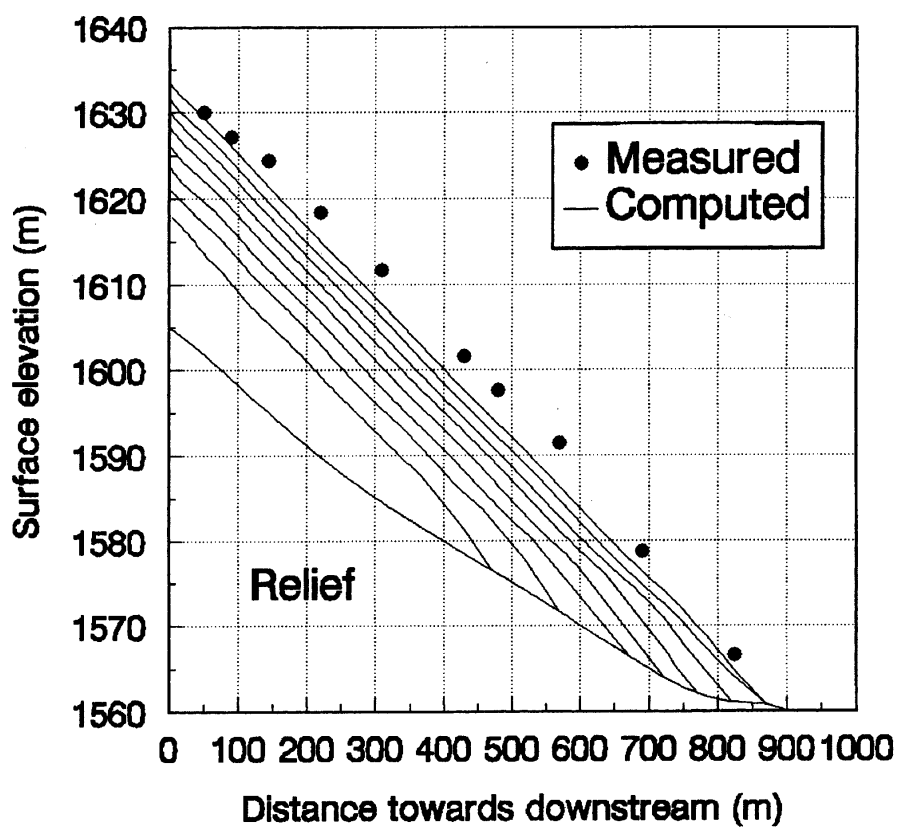

Fig. 4. Central Longitudinal Surface Elevation Profile of Alluvial Fan by Eight Debris Flow Events. Measured Values Correspond to Final Alluvial Fan

both the longitudinal and lateral directions. It is observed that the debris fan develops much faster in the initial stage, quickly slows down afterwards and tends to be stable in the later stage. This is due to the fact that with the enlargement of the fan surface, the supply of debris flow deposits from the upstream entrance is not sufficient enough to cover and increase the extent of existing alluvial fan surface, but mainly to add its thickness. The alluvial fan has the general shape of ellipse or quasi-ellipse in plan view in agreement with Shieh and Tsai (1997). Due to the uneveness of the initial ground surface and the constraint of ravine banks, the

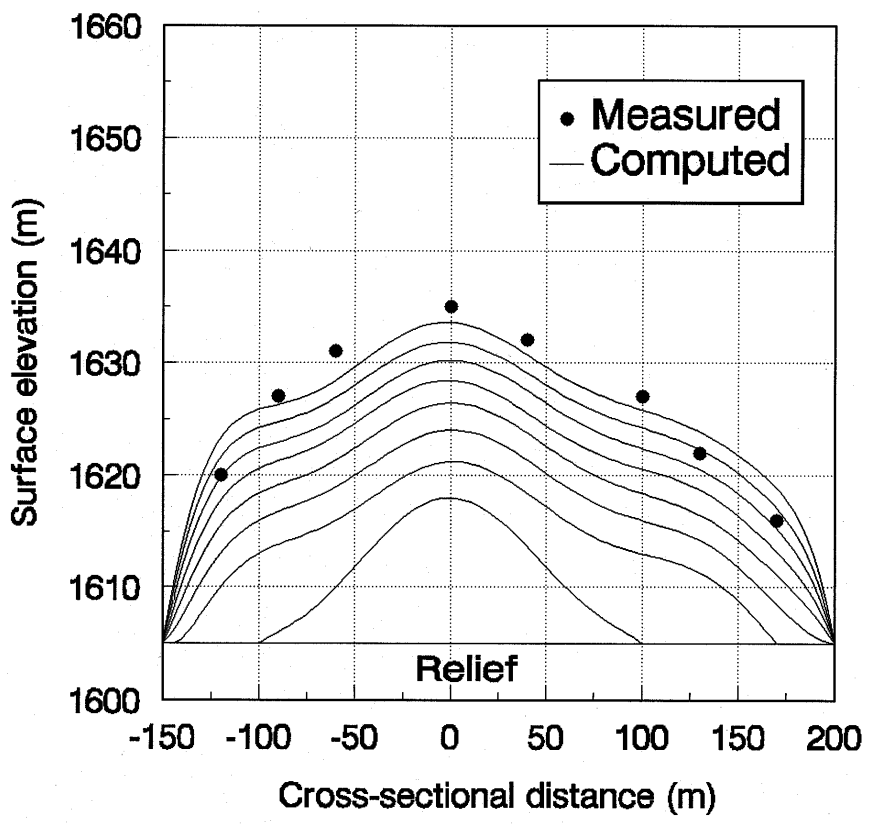

Fig. 5. Cross-sectional Surface Elevation Profile of Alluvial Fan by Eight Debris Flow Events near the Entrance. Measured Values Correspond to Final Alluvial Fan 


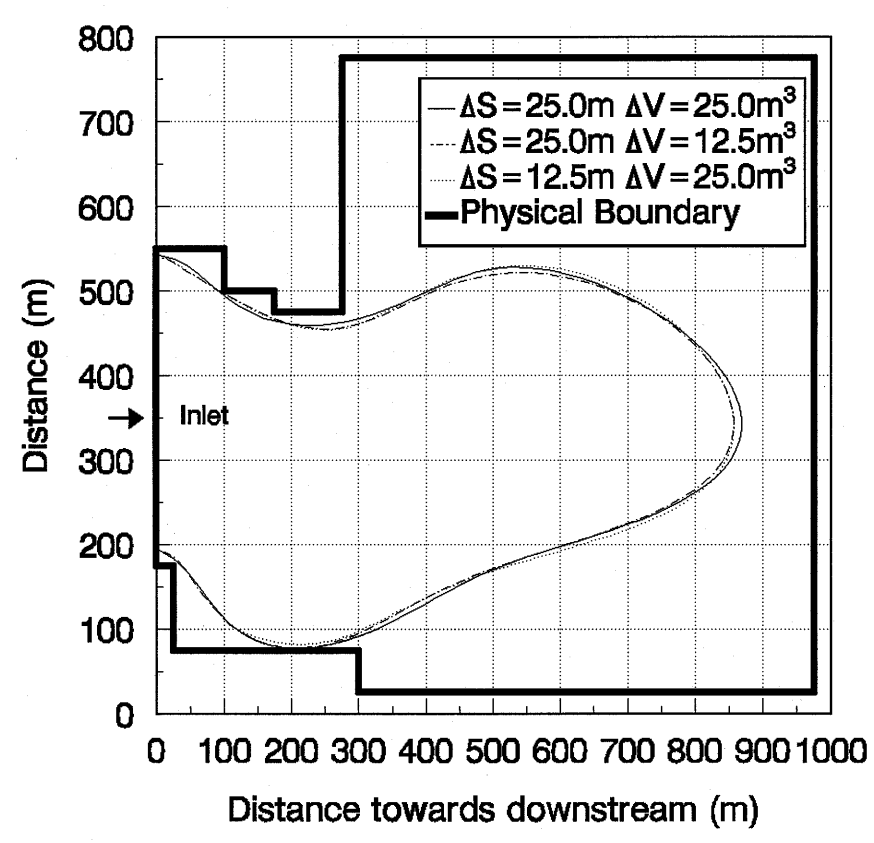

Fig. 6. Influence of Debris Mass Number and Grid Spacing on Numerical Convergence

debris fan is not symmetrical about its longitudinal line. The debris flow is mainly adjusted by the local relief and flow resistance, and finally stops as a result of the loss of energy. The longitudinal and cross-sectional surface slope of the debris fan are much steeper than that of the initial ground. This is due to the strong internal resistance caused by the high viscosity of the liquid slurry and the intense friction of solid coarse particles in the debris flow. The longitudinal surface profile is primarily a straight line, while the cross-sectional one near the entrance of the fan is the combination of convex and concave curves. This is also

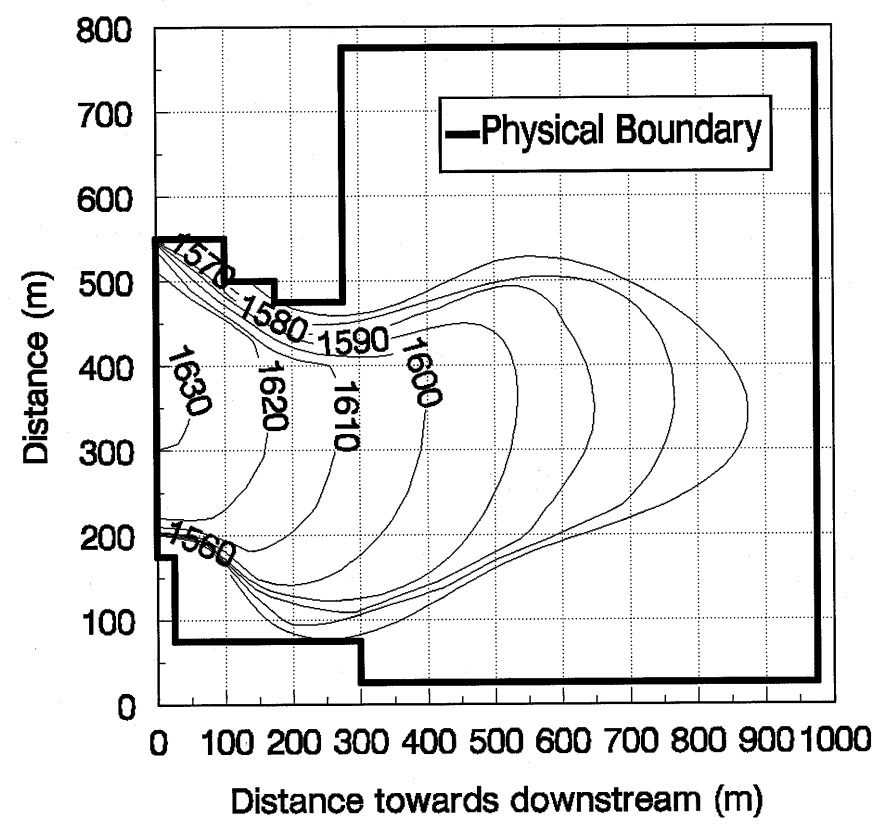

Fig. 7. Contour Map of Computed Surface Elevation for Final Alluvial Fan mainly due to the influence of ravine banks, which enable the debris fan to extend freely downstream but is constrained in the lateral direction.

Two additional numerical tests were also carried out in order to analyze the effects of inlet flow conditions on the formation of the debris fan. The inlet flow conditions of the first test, Test 1, are different from those of the original case of Figure 3 only in that the alluvial fan was formed by one continuous debris flow event lasting 16000 second. Thus the debris fan is formed by one event rather than the original eight, with the total input deposit and discharge rate being held constant. In Test 2 the debris fan was formed by eight discrete flow events as in the original case. However, during each debris flow event, the inlet flow discharge rate was doubled and the time duration was halved. The computed final extent of the debris fan under conditions of Test 1 and 2 is compared with that of the original case in Figure 8.

It is shown that a minor difference of the extent of the debris fan is observed between the original case and Test 1 , while a larger difference is demonstrated in Test 2. Usually, the surface slope of the debris fan is steeper than that of the initial topography on which the debris flow is deposited. If the debris fan is formed by discontinuous flow process, the later fan is superimposed on the previous one and has more energy to spread out. Thus the extent of the debris fan formed by the discontinuous flow in the original case extends a little further than that formed by the continuous flow of Test 1 . The difference in Test 2 arises from the fact that the bed friction force of the debris flow is proportional to the flow velocity, as seen from Equations (5) and (10). Doubling the discharge rate also means doubling the momentum loss. Thus the alluvial fan in Test 2 has a much smaller final extent and assume a steeper slope as compared with the debris fan in the Test 1 and the original case. Therefore, under the condition of the same topography and total amount of deposit mass, the extent of the de-

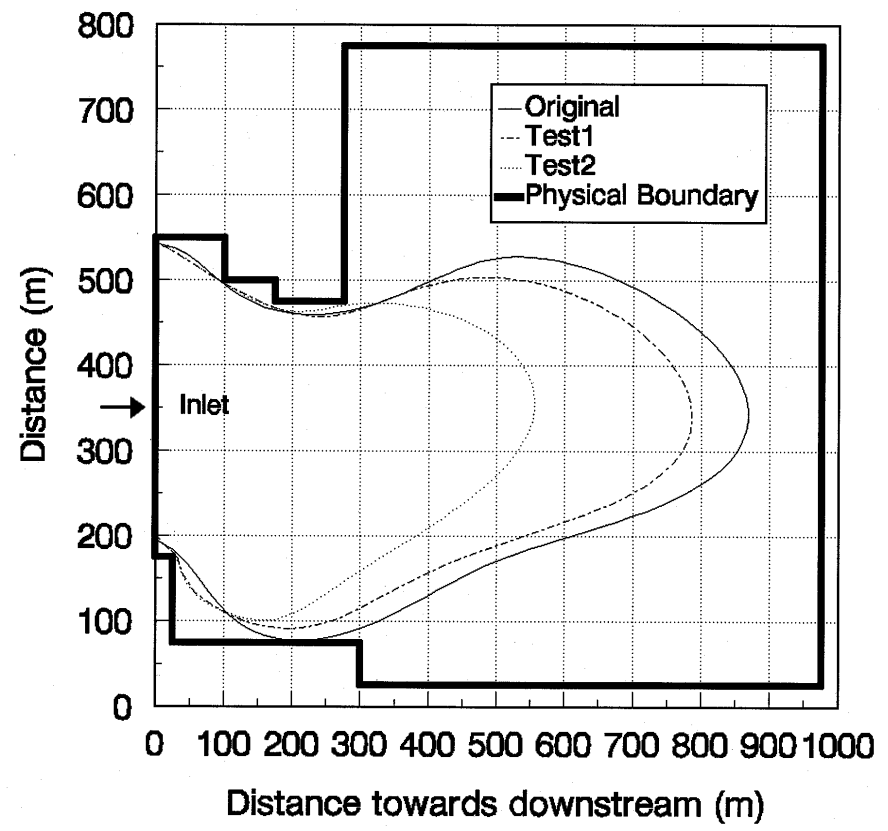

Fig. 8. Comparison of Alluvial Fan Formation by Different Inlet Flow Conditions 
bris fan is much more influenced by the rate of fan formation and less affected by whether the fan is formed continuously or discontinuously.

\section{Conclusions}

Debris flows often cause extensive destruction of property and loss of life in downstream areas. The paper presents a simple and convenient numerical method based on the PIC method to simulate the debris flow inundation in these areas. Both the frictional resistance from the liquid slurry and coarse particles are incorporated in the model. By reproducing a documented viscous debris flow, it has been demonstrated that the debris mass model gives reliable results. The development and configuration features of the depositional fan obtained from numerical simulations are consistent with observations of debris flows in practical debris fields. It is also observed that the shape of the final debris fan is dependent on the discharge rate but less dependent on the duration for a constant total amount of deposits.

The PIC method for the debris mass model is a good approach in that it employs a relatively simple computational algorithm and achieves good accuracy without excessive computational resources. All the computations shown were performed on a $550 \mathrm{MHz}$ PC. The method is especially effective in tracking the moving boundaries and the front and side edges of the debris fan. Further improvements in the model could include the detailed mechanisms of debris flow motion incorporating better rheological models and bed erosion and sedimentation.

\section{Appendix I. References}

Abida, H. and Townsend, R. D. (1994). "Model for routing unsteady flows in compound channels.” J. Hydr. Res., 32(1), 145-153.

Arattano, M. and Savage, W. Z. (1994). "Modeling debris flows as kinematic waves.” Bull. Int. Assn. Engr. Geol., Paris, France, 49(Apr.), 3-13.

BAGNOLD, R. A. (1954). "Experiments on a gravity free dispersion of large solid spheres in a Newtonian fluid under shear." Proc. Royal Soc. London, Ser. A, 225, 49-63.

Coussot, P. (1994). "Steady, laminar, flow of concentrated mud suspensions in open channel.” J. Hydr. Res., 32(4), 535-559.

FEI, X. J. (1991). "The influence of fine grain slurry and debris slurry on debris flow motion." Mountain Research, Vol. 9, No. 3, 143-152. (in Chinese)

Frenette, R., Eyheramendy, D. and Zimmermann, T. (1997). "Numerical modeling of dam-break type problems for Navier-Stokes and granular flows." Proc. First Int. Conf. on Debris-Flow Hazards Mitigation: Mechanics, Prediction, and Assessment, San Francisco, August 7-9. 586-595.

HAN, G. Q. and WANG, D. G. (1996). "Numerical modeling of Anhui debris flow.” J. Hydr. Engr., ASCE, Vol. 122, No. 5, 262-265.

HaRlow, F. H. (1964). "The particle-in-cell computer method for fluid dynamics.” J. Comp. Phys., Vol. 3, 319-343.
HuAng, X. and Garcia, M. H. (1997). "A Perturbation solution for Bingham-plastic mudflows.” J. Hydr. Engr., ASCE, Vol. 123, No. 11, 986-994.

Jeyapalan, J. K., Duncan, J. M. and Seed, H. B. (1983). "Analyses of flow failures of mine tailings dams." J. Geotec. Engr., ASCE, Vol. 109, No. 2, 150-171.

LAigle, D. and Coussot, P (1997). "Numerical modeling of mudflows.” J. Hydr. Engr., ASCE, Vol. 123, No. 7, 617-623.

LI, J., YuAn, J., BI, C. and Luo, D. (1983). “The main features of the mudflow in Jiang-Jia Ravine." Z. Geomorph. N. F., 27(3), 325-341.

MacArthur, R. C. and Schamber, D. R. (1986). "Numerical methods for simulating mudflows." Third Int. Symp. on River Sedimentation, The University of Mississippi. 1615-1623.

Mizuyama, T. and Yazawa, T. (1987). "Computer simulation of debris flow depositional processes." Erosion and Sedimentation in the Pacific Rim, Proc. Corvallis, Oregon, Int. Assn. of Hydrological Sci., 165, 179-190.

O’Brien, J. S., Julien, P. Y. and Fullerton, W. T. (1993). "Two-dimensional water flood and mudflow simulation." J. Hydr. Engr., ASCE, Vol. 119, No. 2, 244-261.

PARKer, G. (1999). "Progress in the modeling of alluvial fans." J. Hydr. Res., Vol. 37, No. 6, 805-825.

ShieH, C. L. and TsaI, Y. F. (1997). "Experimental study on the configuration of debris flow fan.” Proc. First Int. Conf. on Debris-Flow Hazards Mitigation: Mechanics, Prediction, and Assessment, San Francisco, August 7-9. 133-142.

Takahashi, T., Nakagawa, H. and Kuang, S. (1987). "Estimation of debris flow hydrograph on varied slope bed." Erosion and Sedimentation in the Pacific Rim, Proc. Corvallis, Oregon, Int. Assn. of Hydrological Sci., 165, 167-177.

Takahashi, T. (1991). "Debris flows." Int. Assn. for Hydr. Res. Monogr. Ser., Balkema Publishers, Brookfield, Vt., USA.

Tetzlaff, D. M. and Harbaugh, J. W. (1989). Simulating Clastic Sedimentation. Van Nostrand Reinhold, New York.

WAN, Z. and WAnG, Z. (1994). "Hyperconcentrated flow." Int. Assn. for Hydr. Res. Monogr. Ser., Balkema Publishers, The Netherlands.

WANG, G. Q. (1994). “Analysis on the debris flow surges.” Int. J. Sediment Res., Vol. 9, No. 3, 166-175.

Wang, G. Q., Shao, S. D. and Fei, X. J. (1997). "Particle model for alluvial fan formation." Proc. First Int. Conf. on Debris-Flow Hazards Mitigation: Mechanics, Prediction, and Assessment, San Francisco, August 7-9. 143-152.

Wang, G. Q., Shao, S. D. and Fei, X. J. (1998). "Particle model for simulating flow over large areas." J. Hydr. Engr., ASCE, Vol. 124, No. 5, 554-557.

WANG, L. X. and YU, Z. M. (1997). Research Report on Forecast and Identification Methods for Torrent Hazards in Beijing Mountainous Region. Beijing Forestry University Publishing House. (in Chinese)

XIOng, G. et al. (1992). Field Observations and Data Analysis of Debris Flows in the Laogan Ravine and Shawan Ravine. Dongchuan Debris Flow Observation and Research Station, Chinese Academy of Sciences (in Chinese) 


\section{Appendix II. Notation}

The following symbols are used in this paper:

$A=$ area of square grid region

$\vec{a}_{b, t}=$ acceleration of a debris mass

$C_{d m}=$ upper limit volume concentration of debris mixture

$C_{f}=$ volume concentration of liquid slurry

$C_{f 0}=$ critical volume concentration of liquid slurry

$C_{f m}=$ upper limit volume concentration of liquid slurry

$C_{s}=$ volume concentration of coarse grains

$d \quad=$ diameter of grain particles

$d_{0}=$ diameter of particles separating slurry grains and coarse grains

$d_{i}=$ diameter of certain group of grains in the grain size distribution

$g \quad=$ gravitational acceleration

$h \quad=$ flow depth

$h_{b, t}=$ flow depth at the location of a debris mass

$h_{i j}=$ flow depth at a grid point

$k=$ correction coefficient

$N_{i j}=$ number of debris masses within the square grid circling a grid point

$p_{i} \quad=$ weight percent of certain group of grains in the grain size distribution

$\vec{S}_{b, t}=$ flow surface slope at the location of a debris mass

$\vec{S}_{b f, t}=$ bed friction slope of a debris mass

$\vec{S}_{f}=$ bed friction slope of debris flow mixture

$\vec{S}_{l} \quad$ = friction slope for liquid slurries
$\vec{S}_{s} \quad=$ friction slope for coarse solid particles

$\vec{v} \quad=$ depth-averaged velocity vector

$\vec{v}_{b, t}=$ velocity of a debris mass

$\vec{v}_{i j}=$ flow velocity at a grid point

$\vec{X}_{b, t}=$ spatial position of a debris mass

$Z_{0} \quad=$ topographic elevation

$\gamma_{m}=$ specific weight of the debris flow mixture

$\Delta S=$ horizontal grid spacing in both the $\mathrm{x}$ and $\mathrm{y}$ directions

$\Delta t=$ time increment

$\Delta V=$ volume of one debris mass

$\mu_{0}=$ viscosity of water

$\mu_{B}=$ Bingham viscosity of the liquid slurry

$\mu_{m}=$ viscosity of debris flow mixture

$\rho_{l}=$ density of the liquid slurry

$\rho_{m}=$ density of the debris flow mixture

$\rho_{s} \quad=$ density of solid grains

$\tau_{B}=$ Bingham yield stress of the liquid slurry

$\varphi \quad=$ frictional angle

$\phi \quad=$ scale of grain particle size defined by $\phi=\log _{2} d$

\section{Subscripts and Symbols}

$b \quad=$ debris mass

$i j \quad=$ grid point

$l \quad=$ liquid slurry of debris flow

$m$ = debris flow mixture

$s \quad=$ coarse solid particles of debris flow

$\vec{S} g n=$ signs of flow parameters

$t \quad=$ time 